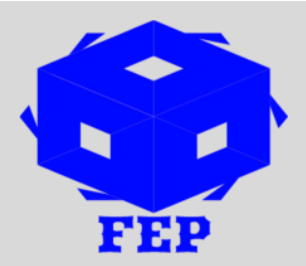

\title{
A STUDY OF DEPRESSION AND SUICIDAL TENDENCIES AMONG THE ADOLESCENTS IN THE BRISTOL, ENGLAND \\ Mike McAllan ${ }^{1}$ \\ ${ }^{1}$ National Health Services, Bristol, England.
}

*Corresponding Author: Mike McAllan

Article Received: 10-09-19

Accepted: 20-12-19

Published: $31-12-19$

Licensing Details: Author retains the right of this article. The article is distributed under the terms of the

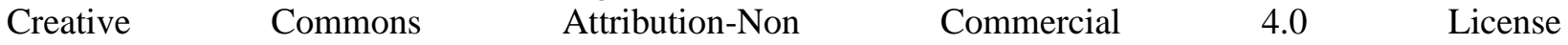
(http://www.creativecommons.org/licences/by-nc/4.0/) which permits non-commercial use, reproduction and distribution of the work without further permission provided the original work is attributed as specified on the Journal open access page.

\section{ABSTRACT}

The study was conducted with the view to investigate the depression and suicidal tendencies among the adolescents in the Bristol city area. The study was conducted using the survey methodology. A total of 223 adolescent were included in the study. The findings of the study were based on the quantitative analysis and using the t-statistics. The results show that among the individuals adolescent we surveyed, almost $40 \%$ were suffering from the depression. Furthermore, when these individuals were compared with the rest of the individuals we surveyed, it was found that depressive adolescent had higher and significant suicidal tendencies. The results show that depression among the adolescent can be a cause of the suicidal behavior. Keywords: Adolescent, Depression, Suicidal Behavior, Tendencies, Students, Bristol.

\section{INTRODUCTION}

Suicide is a global phenomenon and is about intentional self-inflicted death. The suicide of an individual human is result of suffering from extreme tension and emotional pain. Most of the time, individual who commit suicide feel hopelessness about future, severe depression and lack of enough support. Often such individual show some sort of suicide tendencies either through their conversation or behavior. Example of such conversation include talking about suicide, glorifying it, and so on; while, behavioral example includes alcohol consumption, drug addiction, sleep disorder, strange behavior and so on. If someone is observed to be following such behavior or conversation, so they should be referred to psychologist so that proper support can be obtained and reduce the risk of committing suicide. It is estimated that most of the suicides can be prevented since mostly the suicidal state of mind is a temporary condition. In present study, the 
investigation about suicide tendencies is studied in Bristol region. The reason of investigation is that there is high rate of suicide in this particular region. Every year, several youngsters in the Bristol area commit suicide thus making it a serious public health problem. The problem is more common among adolescents. According to Fred (2010), adolescents are higher subject to depression since depression can change or distort the way adolescents can themselves and their lives, and the group members surrounded. A general tendency is that individuals with depression perceive things more negatively and find it difficult to image that any situation or problem can be overcome easily.

\section{Objectives}

The objective of the study is to investigate the suicidal behavior among depressive and normal adolescent in the Bristol.

\section{Hypotheses of the Study}

The study put forward the following hypothesis.

H0: There is insignificant difference between depressive adolescent and normal population in terms of suicidal tendencies.

H1: There is significant difference between depressive adolescent and normal population in terms of suicidal tendencies.

\section{Population and Sampling}

\section{RESEARCH METHODOLOGY}

The population of the study is all adolescents of the Bristol city which is expected to be about 200000. The sampling is based on convenience nonrandom purposive sampling. We used colleges students for sampling and collected data from 223 participants.

\section{Data Collection}

For data collection, we used survey methodology. Suicide probability scale was used for collecting information about suicidal behavior or tendencies. This scale was adapted from Cull and Gill (2004). The surveys were distributed among the participants and data collection was based on five-point Likert scale.

\section{RESULTS}

Our demographic details show that in total, there were 142 male and 81 females participated in our survey. In terms of age, most participants were in age category of 18 to 26 years and the mean age was 21.5 years. Our survey also showed problematic situation that almost $40 \%$ individuals we surveyed were suffering from depression.

Table 1

Suicidal behavior of depressive adolescent and normal Population

\begin{tabular}{lllll}
\hline Sample group & Mean & S.D. & t-test & Sign. level \\
\hline Depressive adolescent & 76.88 & 10.23 & 7.65 & $\mathrm{P}<.01$ \\
Normal population & 64.56 & 9.98 & 0.96 & $\mathrm{P}>.05$ \\
\hline
\end{tabular}


The results showed that the mean value of suicidal behavior or tendencies among depressive adolescent was 76.88 with standard deviation of 10.23 . These results were statistically significant with $t$ value of 7.65 and $p$ value of less than 0.05 . The normal population had suicidal behavior or tendencies of 64.56 with standard deviation of 9.98. These results were statistically insignificant with $t$ value of 0.96 and $p$ value of greater than 0.05 . overall, these results show that in Bristol a lot of individual adolescent suffering from depression which is possible factor of suicidal behavior or tendencies among adolescent.

\section{Discussion}

Our findings show that adolescent have higher depression rate which is leading to the suicidal behavior among the adolescents. These findings are similar to the findings of other studies which shows that depression can lead to the suicidal behavior. For example, study by Blazer, Kessler, Mcgonagle, \& Swartz (1994) shows that people with depression have higher tendencies of suicidal behavior. Similarly, study by Coreyll, Endicott, and Keller (1991) showed that individuals with depression tend to have higher probability of committing suicide. Overall, our results are matching with other studies and the theory.

Our results also highlight the cognitive feature of depression as emphasized by several experts. Accordingly, the negativistic type of thinking among individuals leads to the distorted picture of reality, self, others, and the world around.

\section{CONCLUSION}

The conclusion of the study is that there is high level of suicidal rate in the Bristol. Second conclusion is that there is high prevalence of the depression among the adolescents in the Bristol. Third conclusion is that there is connection between the depression adolescents and their suicide tendencies. Therefore, if suicide rate need to be decreased, then depression may have to overcome.

\section{Recommendations}

Our recommendations are as follows;

The first recommendation is that government must provide suitable support to individuals in order to overcome the suicide problem in the Bristol area.

The second recommendation is that adolescent should be screened for depression and suicidal tendencies and if such tendencies are found, then suitable support must be provided.

Colleges and universities in the region may also keep observing individuals with such tendencies and inform authorities so that timely support can be provided to such individuals.

Parents and other community people need to provide suitable support to the youngsters in order to overcome suicidal problem.

\section{References}

Anderson, R. N. \& Smith, B. L. (2003). Deaths: Leading Causes for 2001. National Vital Statistics Report 2003, 52(9), 1-86.

Bhatt, D. J. \& Meghnathi, R. G. (2004). Suicidal Scale, Unpublished manual, Saurashtra University, Department of Psychology, Rajkot. 
Blazer, D. G., Kessler, R. C., McGonagle, K. A., \& Swartz, M. S. (1994). The prevalence and distribution of major depression in a national community sample: The National Comorbidity Survey. The American Journal of Psychiatry, 151(7), 979-986.

CoryelL, W., Endicott, J. \& Keller, M. B. (1991). Predictors of relapse into major depressive disoroer in a non-clinical population. Journal of American Psychiatry, 148, 1353-1358.

De Man, A. (1999). Correlates of suicide ideation in high school students: The importance of depression. Journal of Genetic Psychology, 160, 105-114.

Donaldson, D., Spirito, A., \& Farnett, E. (2000). The role of perfectionism and depressive cognitions in understanding the hopelessness experienced by adolescent suicide attempters. Child Psychiatry and Human Development, 31, 99-111.

Gotlib, I.H., \& Hammen,C.L. (1992). psychological aspects of depression: Toward a cognative interpersonal integration Chichester, UK: Wiley.

Greenberger, E., Chen, C., Tally, S.R., \& Dong, Q. (2000). Family, peer, and individual correlates of depressive symptomatology among U.S. and Chinese adolescents. Journal of Consulting and Clinical Psychology, 68(2), 209-219.

Maris.R.W., Berman, A.L.,Maltsuberger, J.T.\& Yufit. R.I. (1992). Assessment and prediction of suicide. New York: Guilford.

Sorenson, S.B., Rutter, C.M., \& Aneshensel, C.S. (1991). Depression in the community: An investigation in to age of onset. Journal of Consulting Clinical Psychology, 59, 541-546.

Weissman, M.M., \& Olfson, M. (1995). Depression in Women; implications for health care. Research Science, 269, 799-801. 